\title{
Mechanical and economical impacts of adding polymers into asphalt mixtures
}

\author{
Mena Souliman ${ }^{1, *}$, Waleed Zeiada ${ }^{2}$, and Lubinda Walubita ${ }^{3}$ \\ ${ }^{1}$ University of Texas at Tyler3900 University Blvd, Tyler, TX 75799 \\ ${ }^{2}$ Department of Civil and Environmental Engineering, University of Sharjah P.O. Box 27272, \\ Sharjah, United Arab Emirates \\ ${ }^{3}$ The Texas A\&M University System, 3135 TAMU, College Station, TX 77843-3135
}

\begin{abstract}
Load associated fatigue cracking is one of the major distress types occurring in flexible pavements. Flexural bending beam fatigue laboratory test has been used for several decades and is considered an integral part of the Superpave advanced characterization procedure. One of the most significant solutions to sustain the fatigue life for an asphaltic mixture is to add sustainable materials such as polymers to the asphalt mixture. A laboratory testing program was performed on two gap-graded mixtures: unmodified and polymer-modified asphalt mixtures. Strain controlled fatigue tests were conducted according to the AASHTO T321 procedure. The results from the beam fatigue tests indicated that the polymer-modified gap graded mixture would have much longer fatigue life compared to the reference (unmodified) mixture. In addition, a mechanistic analysis using 3D-Move software coupled with a cost-effectiveness analysis study based on the fatigue performance on the three mixtures were performed. Overall, the analysis showed that the polymer-modified asphalt mixture exhibited significantly higher cost-effectiveness compared to unmodified HMA mixture. Although polymer-modification increases the cost of the material, the analysis showed that it is more cost effective than the unmodified mixture.
\end{abstract}

\section{Introduction}

In 2008, a first cooperative effort between Arizona State University (ASU) and the Swedish Road Administration (SRA) took place in testing unmodified, Asphalt rubber and polymermodified gap-graded mixtures placed on Malmo E6 External Ring Road in Sweden. In 2009, SRA and ASU undertook another joint effort to test three types of gap-graded mixtures: unmodified, Asphalt Rubber-modified mixtures, as well as polymer-modified asphalt mixtures placed on highway E18 between the interchanges Järva Krog and Bergshamra in the Stockholm area of Sweden. This paper concentrates on the comparison between unmodified and polymer-modified gap-graded mixtures only.

\footnotetext{
*Corresponding author: msouliman@uttyler.edu
} 
Rice specific gravities for the mixtures were determined. Beam specimens were prepared according to the Strategic Highway Research Program (SHRP) and the American Association of State Highway and Transportation Officials (AASHTO): SHRP M-009 and AASHTO T321-03 (equivalent European test standards are: EN12697-24 A to D). Air voids, thickness and bulk specific gravities were measured for each test specimen and the samples were stored in plastic bags until testing.

The Swedish Road Administration provided information stating that the field compaction produced air voids was around 3.0\% for all mixtures. The original mix designs were done using the Marshall Mix design method. Table 1 shows the reported average aggregate gradations for both mixtures. The in-situ mixture properties of the Stockholm pavement test sections are also reported in Table 1, which include percent binder content by mass of the mix, Marshall percent void content by volume of the mixture, and maximum theoretical specific gravity of the mixes $\left(\mathrm{G}_{\mathrm{mm}}\right)$ estimated at the ASU laboratory. The base bitumen used was Pen 70/100.

Table 1. Average aggregate gradations and mixture characteristics.

\begin{tabular}{|c|c|c|c|}
\hline \multirow{8}{*}{$\begin{array}{l}\text { Percent } \\
\text { Passing }\end{array}$} & $\begin{array}{l}\text { Sieve Size } \\
\quad(\mathbf{m m})\end{array}$ & $\begin{array}{c}\text { Reference } \\
\text { Unmodified } \\
\text { Mixture } \\
\end{array}$ & $\begin{array}{c}\text { Polymer- } \\
\text { Modified } \\
\text { Mixture } \\
\end{array}$ \\
\hline & 22.4 & 100 & 100 \\
\hline & 16 & 98 & 98 \\
\hline & 11.2 & 65 & 65 \\
\hline & 8 & 38 & 38 \\
\hline & 4 & 23 & 23 \\
\hline & 2 & 21 & 21 \\
\hline & 0.063 & 10.5 & 10.5 \\
\hline \multicolumn{2}{|c|}{ Binder Content (\%) } & 5.9 & 5.9 \\
\hline \multicolumn{2}{|c|}{ Air Voids (\%) } & 2.6 & 2.6 \\
\hline \multicolumn{2}{|c|}{$\mathbf{G}_{\mathbf{m m}}$} & 2.464 & 2.456 \\
\hline
\end{tabular}

Previous publications showed that polymer-modified mixtures had superior fatigue resistance performance over the unmodified HMA mixture as shown in Figure 1 (1). The remaining unanswered question is: does polymer-modified mixtures represent costeffective solutions to resist fatigue cracking compared to unmodified HMA mixtures? 


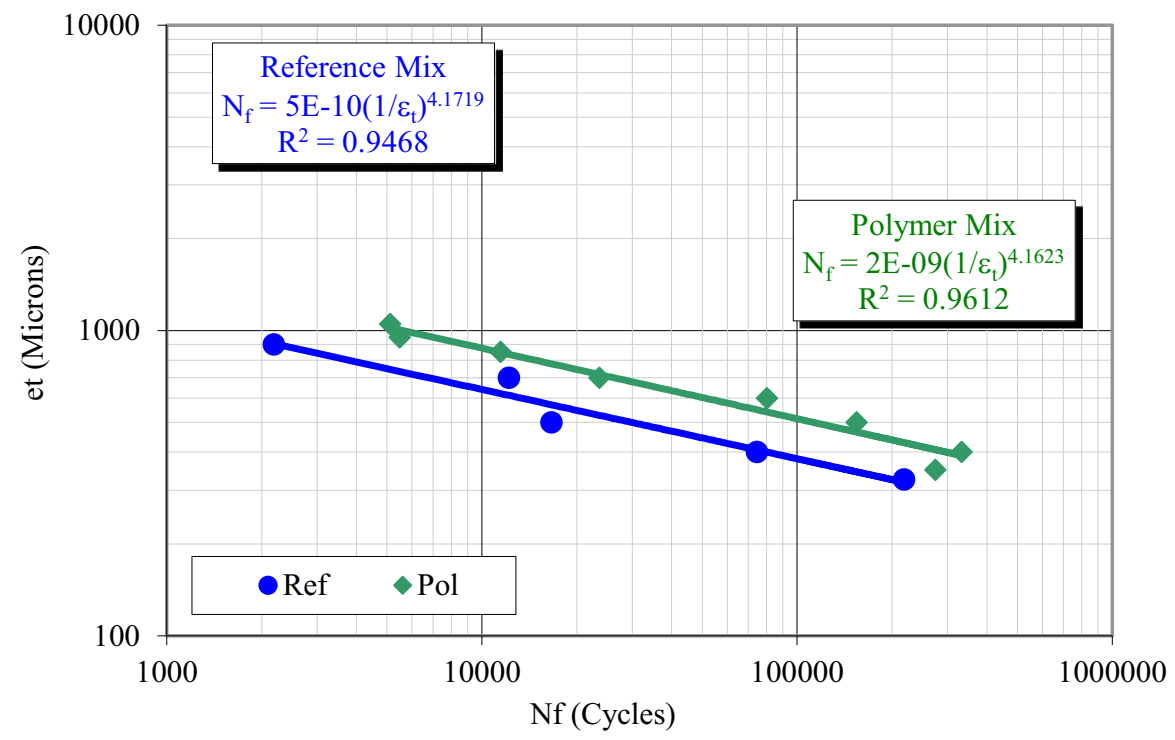

Fig. 1. Fatigue life comparison between the reference unmodified mixture and polymer-modified mixture at $21^{\circ} \mathrm{C}$ using $\mathrm{N}_{\mathrm{f}}$ at $50 \%$ of the initial stiffness [1]

\section{Objective}

The objective of this study was to assess the cost-effectiveness of polymer modified asphalt mixtures as related to fatigue performance. The study combines the results of the mechanical fatigue laboratory evaluations with the long-term mechanistic performance as well as the cost of polymer-modified mixtures to assess the full benefits of such additives relative to their added costs.

\section{Literature search}

Von Quintus et al. [2] evaluated the benefits of using polymer-modified mixtures based on accelerated field pavement testing data from 36 pavement sections in the United States. It was evident that the use of polymer-modification certainly extends the service life of flexible pavements and HMA overlays. The study concluded that pavements incorporating polymer-modified mixtures showed lower amounts of fatigue cracking, transverse cracking and rutting, which extended the pavement service lives by 5 to 10 years.

Another study was conducted at the Asphalt Institute [3] to compare polymer-modified mixtures with unmodified HMA mixtures in terms of the potential to reduce occurrence of distresses and the increase in pavement life as well as conducting a life cycle cost analysis (LCCA) between the two mixtures. Eighty-four Long Term Pavement Performance (LTPP) sections were utilized in the study. Damage index (observed number of cycles to failure in the field over the predicted number of cycles to failure) was computed for the two mixtures to obtain the difference in expected service lives. It was found that polymer-modified mixtures had an extended life that ranged from one to ten years depending on the site factor (e.g., foundation, water table, drainage, etc.). In addition, the LCCA showed a potential saving ranging from $4.5 \%$ to $14 \%$ when polymer-modified mixtures are used compared to unmodified HMA mixtures. 
Timm et al. [4] compared the structural responses of highly polymer-modified (HPM) asphalt on the NCAT test track with a control section. The structural behaviors of both HPM and the control section in response to temperature changes were characterized by exponential functions. At both a low temperature of $50^{\circ} \mathrm{F}$ and an intermediate temperature of $80^{\circ} \mathrm{F}$, the HPM section experienced higher average strains compared with that of the control section (partly owing its thickness). This implies that the HPM section would have a lower strain at intermediate temperatures if the thickness of the two materials is similar. At a high temperature of $109^{\circ} \mathrm{F}$, the control section experienced higher average strains compared with the HPM, despite a 1.4 in. $(35 \mathrm{~mm})$ thickness advantage over the HPM. The aggregate base experienced higher average vertical stresses in the HPM section than the control section at all temperatures. The accelerated field pavement testing data indicated that the HPM is effective at reducing HMA layer thickness without significant changes in performance.

The improved performance of polymer-modified pavements compared with unmodified bitumen pavements has relatively resulted from improved rheological properties of the modified asphalt binder. Modified bituminous materials can introduce measurable benefits to highway maintenance and construction divisions, in terms of better-performance and longer lasting roads, as well as cost savings in the road service life. The use of asphalt polymer modifications seems to enhance the fatigue resistance, as illustrated in a number of other studies $[5,6]$. What has to be ascertained in practice is the degree of modification of the asphalt mixtures that takes place and its cost effectiveness. A detailed comparison between the two mixtures (unmodified and polymer-modified) is needed to quantify the true cost effectiveness of polymer-modified asphalt mixtures as related to fatigue performance.

\section{Mechanistic-empirical analysis of unmodified and polymer- modified pavements}

The concept of Mechanistic-Empirical pavement design is a comprehensive approach for the design of pavement layers thickness. A mechanistic approach explains the phenomena caused by the physical action. In the pavement thickness design, the phenomena are the stresses, strains and deflections within a pavement structure and the physical causes are the loads, climatic conditions, and material properties of the pavement structure. In this part of the study, the mechanistic-empirical approach has been used to estimate the performance life of the unmodified HMA and polymer-modified pavements based on the fatigue characteristics of the mixtures.

Two pavement structures; thin and thick, and two vehicle speeds; 16 and $113 \mathrm{~km} / \mathrm{h}(10$ and $70 \mathrm{mph}$ ), were selected for the analyses. The thin pavement structure consisted of 100 $\mathrm{mm}$ (4 inches) of a surface layer over $150 \mathrm{~mm}$ (6 inches) of crushed aggregate base and an infinite granular subgrade, whereas the thick pavement structure consisted of $200 \mathrm{~mm}(8$ inches) of surface layer over same base and subgrade as the thin pavement. The surface layer can either be a reference unmodified HMA or polymer modified.

The fatigue life $\left(\mathrm{N}_{\mathrm{f}}\right)$ of the asphalt concrete layer is a function of the tensile strain $\left(\varepsilon_{\mathrm{t}}\right)$. The number of load cycles to fatigue failure increases exponentially with a decrease in strain level. The fatigue relationship can be modeled as follows:

$$
N_{f}=k_{1}\left(\frac{1}{\varepsilon_{t}}\right)^{k_{2}}
$$

where $\mathrm{k}_{1}$ and $\mathrm{k}_{2}$ are the regression constants at $21.1^{\circ} \mathrm{C}\left(70^{\circ} \mathrm{F}\right)$, which is the critical temperature for fatigue cracking. 
In order to predict the long-term fatigue performance of the reference unmodified HMA and the polymer-modified pavements, laboratory beam fatigue tests were conducted according to AASHTO T321 along with an analytical model were used. The analytical 3DMove model [7, 8], which is based on a continuum-based finite-layer approach, was used in this study. The 3D-Move Analysis model can account for important pavement factors such as the moving traffic-induced complex 3D contact stress distributions (normal and shear) of any shape, vehicle speed, and viscoelastic material characterization for the asphalt concrete layer. The 3D-Move software, developed by the Western Regional Superpave Center at the University of Nevada, Reno, was used to calculate the tensile strains at the bottom of the asphalt concrete layer constructed with HMA and polymer-modified mixtures. Input parameters for the analyses include pavement layer thicknesses, materials properties, and traffic loads and speeds. Dynamic moduli measured at 5 temperatures $(-10,4.4,21.1,37.8$, and $\left.54.4^{\circ} \mathrm{C}\right)$ and six frequencies $(0.1,0.5,1,5,10,25 \mathrm{~Hz})$ for each HMA and polymermodified mixtures [9] were used in the analysis (Figure 2). The resilient moduli of the base and the subgrade were assumed to be $193 \mathrm{MPa}(28 \mathrm{ksi})$ and $55 \mathrm{MPa}(8 \mathrm{ksi})$, respectively. The pavements were loaded with a standard single axle load of $80 \mathrm{kN}$ (18-kips) over dual tires spaced at $304.8 \mathrm{~mm}$ (12 inches) with an inflation pressure of $827.4 \mathrm{kPa}(120 \mathrm{psi})$.

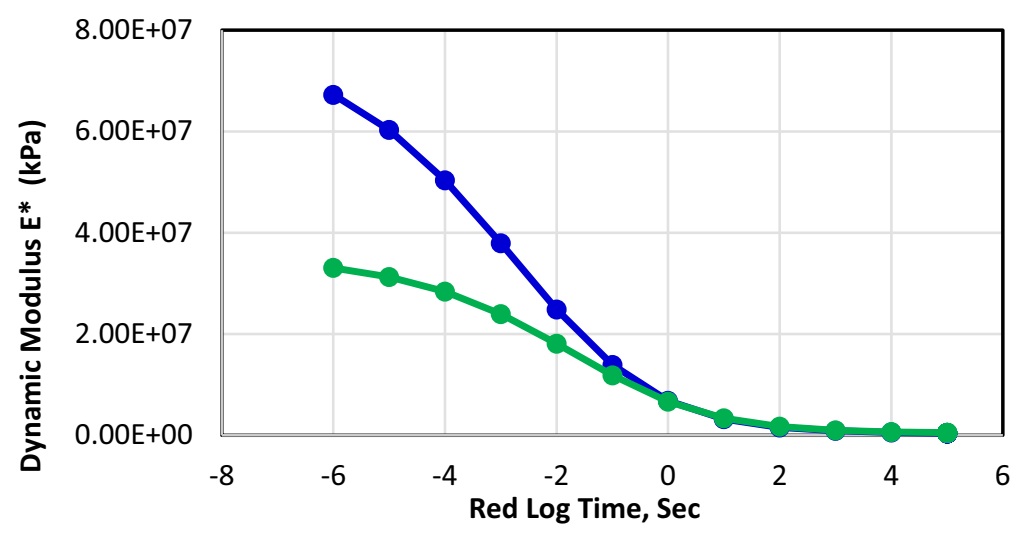

- Reference Conventional Mixture $\quad-$ Polymer-modified Mixture

Fig. 2. Average $E^{*}$ master curves for HMA and polymer-modified mixtures [9].

Tensile strains at the bottom of the asphalt concrete layer were analyzed at two locations; under the center of one tire and midway between the centers of the two tires in order to identify the maximum tensile strain. A summary of the results of the maximum tensile strains is presented in Table 2. Utilizing the laboratory fatigue performance equations developed from the beam fatigue tests (Table 2), the fatigue lives for reference unmodified HMA and polymer-modified mixtures were calculated based on the maximum tensile strains determined from the 3D-Move analyses. The number of cycles calculated at the maximum tensile strain represents the fatigue life of the pavement constructed with reference unmodified HMA and polymer-modified mixtures. The ratio of fatigue life of the polymer-modified mixtures over the fatigue life of the reference unmodified HMA mixture are presented in Table 2. 
Table 2. Mechanistic fatigue analysis results.

\begin{tabular}{|c|c|c|c|c|c|c|c|}
\hline Pavement & $\begin{array}{c}\text { Velocity } \\
(\mathbf{k m} / \mathbf{h})\end{array}$ & $\begin{array}{l}\text { Strain at the } \\
\text { bottom of the } \\
\text { Asphalt Layer } \\
\text { (microns) }\end{array}$ & $\mathbf{k}_{1}$ & $\mathbf{k}_{2}$ & $\begin{array}{c}\mathbf{N}_{\mathrm{f}} \\
\text { (Cycles)* }\end{array}$ & $\begin{array}{c}\text { Fatigue } \\
\text { Ratio }\end{array}$ & $\begin{array}{c}\text { Average } \\
\text { Fatigue } \\
\text { Ratio }\end{array}$ \\
\hline \multicolumn{8}{|c|}{ Reference Unmodified Hot Mix Asphalt } \\
\hline \multirow{2}{*}{ Thin } & 16 & 264 & \multirow{4}{*}{$5.00 \mathrm{E}-10$} & \multirow{4}{*}{4.17} & 416,926 & 1 & \multirow{4}{*}{1} \\
\hline & 113 & 194 & & & $1,521,577$ & 1 & \\
\hline \multirow{2}{*}{ Thick } & 16 & 135 & & & $6,852,999$ & 1 & \\
\hline & 113 & 94 & & & $30,372,021$ & 1 & \\
\hline \multicolumn{8}{|l|}{ Thick } \\
\hline \multicolumn{8}{|c|}{ Polymer-modified Mixture } \\
\hline \multirow{2}{*}{ Thin } & 16 & 273 & \multirow{4}{*}{$2.00 \mathrm{E}-09$} & \multirow{4}{*}{4.16} & $1,338,423$ & 3.2 & \multirow{4}{*}{2.8} \\
\hline & 113 & 216 & & & $3,545,703$ & 2.3 & \\
\hline \multirow{2}{*}{ Thick } & 16 & 138 & & & $22,862,988$ & 3.3 & \\
\hline & 113 & 104 & & & $74,160,270$ & 2.4 & \\
\hline
\end{tabular}

*Note that one cycle in the laboratory fatigue test is not equivalent to one ESAL in the field since there is a shift factor between laboratory and field conditions. The estimated $\mathrm{N}_{\mathrm{f}}$ cycles in the laboratory is used in this paper for the purpose of comparing material alternatives only and does not affect the accuracy of calculations.

The number of repetitions to fatigue cracking was calculated using the highest strain and the appropriate k values. Summary of results that the maximum tensile strains for different combinations of pavement structures, materials, and speeds are presented in Table 2. The figure shows that, at the same thickness and vehicle speed levels, similar tensile stains at the bottom of the asphalt layer were observed among the three asphalt mixtures. The table also illustrate that, within each mixture, thicker pavement structures experience less tensile strains at the bottom of the asphalt layer compared to thinner pavements. Lastly, it was noticed that the tensile strain at the bottom of the asphalt concrete layer increases by decreasing vehicle speed from $113 \mathrm{~km} / \mathrm{h}(70 \mathrm{mph})$ to $16 \mathrm{~km} / \mathrm{hr}(10 \mathrm{mph})$ since the loading rate affects the modulus of the asphaltic material.

Table 2 shows the tensile strains, fatigue constants $\left(\mathrm{k}_{1}\right.$ and $\left.\mathrm{k}_{2}\right)$ and number of load cycles to failure $\left(\mathrm{N}_{\mathrm{f}}\right)$ for all combinations of pavement structures, materials, and speeds. The ratio of fatigue life of each mixture over the fatigue life of the control of HMA mixture is also shown in Table 2 .

Based on the results presented in Table 2, the following observations can be made:

- Polymer-modified mixtures showed slightly larger tensile strains at the bottom of the surface layer as compared to unmodified mixtures.

- Polymer-modified mixtures has a much higher fatigue life as compared to the unmodified HMA mixtures. A fatigue ratio of 2.8 of the Polymer-modified mixtures is obtained as compared to the unmodified mixture, which implies that the pavement with polymer modifications is expected to have 2.8 times the fatigue life of the corresponding pavement with an HMA layer.

- Within each mixture, the thicker surface layer $(200 \mathrm{~mm})$ has significantly lower tensile strain compared to the corresponding thin asphalt concrete layer $(100 \mathrm{~mm})$. This resulted in higher fatigue lives for thick pavements compared to thin pavements.

- Within each mixture, the tensile strain at the bottom of the asphalt concrete layer increases by decreasing vehicle speed from $113 \mathrm{~km} / \mathrm{h}(70 \mathrm{mph})$ to $16 \mathrm{~km} / \mathrm{h}(10 \mathrm{mph})$. This resulted in higher fatigue lives for pavements loaded with high vehicle speed compared to low vehicle speed. 


\section{Cost comparison based on fatigue performance}

In order to evaluate the economic values of all mixtures based on fatigue performance, a pavement section of $1.6 \mathrm{~km}$ ( 1 mile) with $4.57 \mathrm{~m}$ (15 feet) wide single lane was considered. Based on the assumed density of $110 \mathrm{lb}$./sq.-yd.-in, the required quantities for paving 100 and $200 \mathrm{~mm}$ (4 and 8 inch) thick asphalt concrete layers are as follows:

- For the $100 \mathrm{~mm}$ thick asphalt concrete layer: $1600 \mathrm{~m}$ (length) x $4.57 \mathrm{~m}$ (width) x $100 \mathrm{~mm}$ (thickness) x $59.67 \mathrm{~kg} / \mathrm{m} 2(110 \mathrm{lb} . /$ square yard $)=1,936$ tons.

- For the $200 \mathrm{~mm}$ thick asphalt concrete layer: $1600 \mathrm{~m}$ (length) x $4.57 \mathrm{~m}$ (width) x $100 \mathrm{~mm}$ (thickness) x $59.67 \mathrm{~kg} / \mathrm{m} 2(110 \mathrm{lb} . /$ square yard $)=3,872$ tons.

The cost of production of 100 tons of HMA mixture can be calculated as follows assuming typical current material costs:

- Optimum binder content in the mixture $=4.5 \%$ by total weight of mixture.

- Quantity of binder required $=4.5$ tons

- Quantity of aggregates $=95.5$ tons

- Total cost of binder@ $@ \$ 600 /$ ton =4.5 x600=\$2,700

- Total cost of aggregates @ \$14/ton=95.5 x $14=\$ 1,337$

- Cost of plant and equipment lump sum for 100 tons of HMA mixture $=\$ 2,500$

- Total cost for the production of 100 tons of the HMA mixture =

- $\$ 2,700+\$ 1,337+\$ 2500=\$ 6,537$

- Therefore, the cost of HMA per ton $=\$ 65.37$

The additional cost for polymer-modified mixtures per ton was estimated to be around $\$ 0.15$ per ton of asphalt mixture [10]. Therefore, the estimated cost of one ton of polymermodified mixture is $\$ 65.37$ (Cost of HMA per ton) $+\$ 0.15=\$ 65.52$ per ton. Knowing the cost of the HMA and polymer-modified mixtures per ton, the required cost to pave $1.6 \mathrm{~km}$ (1 mile) of the pavement section with various mixtures were calculated as follows:

- Cost to pave one mile of $100 \mathrm{~mm}$ thick HMA $=1,936$ tons $\times \$ 65.37$ ton $=\$ 126,556$

- Cost to pave one mile of $200 \mathrm{~mm}$ thick HMA $=3,872$ tons $\times \$ 65.37 /$ ton $=\$ 253,113$

- Cost to pave one mile of $100 \mathrm{~mm}$ thick polymer-modified mixture $=1,936$ tons $\mathrm{x}$ $\$ 65.52 /$ ton $=\$ 126,847$

- Cost to pave one mile of $200 \mathrm{~mm}$ thick polymer-modified mixture $=3,872$ tons $\mathrm{x}$ $\$ 65.52 /$ ton $=\$ 253,693$

Combining the cost of the pavement per mile with the fatigue lives from the mechanistic-empirical analyses, the costs of 1,000 cycles of fatigue life per pavement mile were calculated for the polymer-modified mixtures and their corresponding reference unmodified HMA mixture. This cost figure was derived by dividing the total cost of the 1mile pavement section by the number of 1000 cycles to fatigue failure (i.e., $\mathrm{N}_{\mathrm{f}} / 1000$ as summarized in Table 3). In other words, it is the cost of a $1.6 \mathrm{~km}$ (1-mile) pavement section for every 1,000 cycles of fatigue life were determined and are summarized in Table 3. A lower cost per mile per 1,000 cycles of fatigue life indicates more cost-effectiveness. 
Table 3. Cost calculation per mile per 1,000 cycles fatigue performance.

\begin{tabular}{|c|c|c|c|c|}
\hline Pavement & $\begin{array}{l}\text { Velocity } \\
(\mathbf{k m} / \mathbf{h})\end{array}$ & $\begin{array}{c}\text { Cost } \\
(\$ / \text { ton })\end{array}$ & $\begin{array}{c}\text { Cost of Pavement per } \\
1,000 \text { Cycles of Fatigue } \\
\text { Life per } 1.6 \mathrm{~km} \text { (1-mile) } \\
(\$)\end{array}$ & $\begin{array}{c}\text { Average Cost of } \\
\text { Pavement per } 1,000 \\
\text { Cycles of Fatigue Life } \\
\text { per } 1.6 \mathrm{~km}(1-\mathrm{mile})(\$)\end{array}$ \\
\hline \multicolumn{5}{|c|}{ Reference Unmodified Hot Mix Asphalt } \\
\hline \multirow{2}{*}{ Thin } & 16 & \multirow{4}{*}{65.37} & 303 & \multirow{4}{*}{108} \\
\hline & 113 & & 84 & \\
\hline \multirow{2}{*}{ Thick } & 16 & & 37 & \\
\hline & 113 & & 8 & \\
\hline \multicolumn{5}{|c|}{ Polymer-modified Mixture } \\
\hline \multirow{2}{*}{ Thin } & 16 & \multirow{4}{*}{65.52} & 95 & \multirow{4}{*}{36} \\
\hline & 113 & & 36 & \\
\hline \multirow{2}{*}{ Thick } & 16 & & 11 & \\
\hline & 113 & & 3 & \\
\hline
\end{tabular}

\section{Cost-effectiveness analysis}

Cost-effectiveness analysis is an economic evaluation technique for comparing the cost paid to the gained benefit for the purpose of evaluating alternatives. Several methods are available to evaluate the cost-effectiveness of alternatives [11, 12]. For the purpose of comparing the cost-effectiveness of the unmodified and polymer-modified mixture, a simple approach is used in this study by dividing the expected performance of each mixture by its cost as shown in Equation 2.

$$
\text { Cost Effectiveness }=\frac{\text { Expected Performance }}{\text { Mixture Unit Cost }}
$$

Equation 2 can be viewed as estimating the "bang for the buck" for each case. The alternative that provides the greatest ratio of the benefit to the cost is the "best." In this analysis, only the initial material's cost is used. Other costs, such as maintenance and salvage value, are ignored.

In this case, the expected performance is the predicted number of fatigue cycles to failure (Table 2), while the mixture unit cost was determined as the cost of one mile as determined earlier. Table 4 shows the coast effectiveness of different cases. For example, the cost-effectiveness for a thin (4") unmodified mixture at a vehicle velocity of $16 \mathrm{~km} / \mathrm{h}$ will be the expected performance life $(416,926$ cycles $)$ divided by the unit cost $(\$ 126,556$ per cost of one mile), which will result in 3.3 cycles/cost of one mile.

Table 4. Cost-effectiveness of all mixture combinations.

\begin{tabular}{|c|c|c|c|c|c|c|}
\hline Pavement & $\begin{array}{c}\text { Velocity } \\
(\mathbf{k m} / \mathbf{h})\end{array}$ & $\begin{array}{l}\text { Cost of } \\
\text { one } \\
\text { mile (\$) }\end{array}$ & $\begin{array}{c}\mathbf{N}_{\mathrm{f}} \\
\text { (Cycles) }\end{array}$ & $\begin{array}{c}\text { Cost- } \\
\text { Effectiveness } \\
\text { (Cycles/ } \\
\text { Cost of One } \\
\text { Mile) } \\
\end{array}$ & $\begin{array}{c}\text { Average } \\
\text { Cost- } \\
\text { Effectiveness } \\
\text { (Cycles/ cost } \\
\text { of one mile) } \\
\end{array}$ & $\begin{array}{c}\text { Average } \\
\text { Cost- } \\
\text { Effectiveness } \\
\text { Ratio }\end{array}$ \\
\hline \multicolumn{7}{|c|}{ Reference Unmodified Hot Mix Asphalt } \\
\hline \multirow{2}{*}{ Thin } & 16 & 126,556 & 416,926 & 3.3 & \multirow{4}{*}{41.2} & \multirow{4}{*}{1} \\
\hline & 113 & 126,556 & $1,521,577$ & 11.9 & & \\
\hline \multirow{2}{*}{ Thick } & 16 & 253,113 & $6,852,999$ & 27.0 & & \\
\hline & 113 & 253,113 & $30,372,021$ & 122.4 & & \\
\hline \multicolumn{7}{|c|}{ Polymer-modified Mixture } \\
\hline \multirow{2}{*}{ Thin } & 16 & 126,847 & $1,338,423$ & 10.6 & \multirow{4}{*}{105.2} & \multirow{4}{*}{2.6} \\
\hline & 113 & 126,847 & $3,545,703$ & 28.0 & & \\
\hline \multirow{2}{*}{ Thick } & 16 & 253,693 & $22,862,988$ & 90.1 & & \\
\hline & 113 & 253,693 & $74,160,270$ & 292.3 & & \\
\hline
\end{tabular}


Based on the results presented in Table 4, the following observations can be made:

- The polymer-modified mixtures resulted in the higer cost-effectiveness compared to the unmodified mixtures. Cost-effectiveness values of 105.2 and 41.2 cycles per cost of one mile are obtained for the polymer-modified and the unmodified mixtures, respectively. Moreover, the average cost-effectiveness ratio for polymer-modified mixtures (calculated as the average cost-effectiveness of polymer-modified mixtures divided by average costeffectiveness of the reference mixtures) was 2.6.

- Within each mixture, the thick surface layer $(200 \mathrm{~mm})$ has significantly higher costeffectiveness compared to the corresponding thin surface layer $(100 \mathrm{~mm})$.

- Within each mixture, it was noticed that the cost-effectiveness increases by increasing vehicle speed from $16 \mathrm{~km} / \mathrm{h}(10 \mathrm{mph})$ to $113 \mathrm{~km} / \mathrm{h}(70 \mathrm{mph})$.

\section{Conclusions and recommendations}

Based on the results presented, the following observations are drawn:

- Polymer-modified mixtures exhibited significantly higher cost-effectiveness (larger cycles per cost of one mile) compared to reference HMA mixtures. On average, the costeffectiveness of polymer-modified mixtures was 2.6 times higher than the unmodified mixture.

- The thicker pavement (200 $\mathrm{mm}$ asphalt concrete) is more cost-effective than the thinner pavements (100 $\mathrm{mm}$ asphalt concrete) for the same material and vehicle speed.

- The cost-effectiveness increase by increasing vehicle speed from $16 \mathrm{~km} / \mathrm{h}$ to $113 \mathrm{~km} / \mathrm{h}$ for the same material and pavement thickness.

Based on the results of this study, it is recommended that transportation agencies would increase the use of polymer-modified mixtures in cases where fatigue problems are common. More analyses are needed to evaluate the cost-effectiveness of these modifiers as related to other types of distresses.

\section{References}

1. Souliman, M. I., Kaloush, K. E. Assessment of the Extended Fatigue Life for Rubber and Polymer Modified Asphalt Mixtures Using Flexural Bending Beam Fatigue Test. Jordan Journal of Civil Engineering, Vo. 5, No. 2, 2011, pp. (210-215).

2. Von Quintus, H., J. Mallela, and M. Buncher, Quantification of the Effect of Polymer Modified Asphalt on Flexible Pavement Performance. Transportation Research Record: Journal of the Transportation Research Board, No. 2001, Transportation Research Board of the National Academies, Washington, D.C, pp. 141-154 (2007)

3. Buncher, M., Quantifying the Benefits of Polymer Modified Asphalt-Reducing Pavement Distress. Asphalt Institute : IS-215. (2009).

4. Timm, D.H., M.M. Robbins, and R. Kluttz. Full-Scale Structural Characterization of a Highly-Polymer-Modified Asphalt Pavement. Preprint CD, prepared for the 90th Annual Meeting of the Transportation Research Board, Washington, D.C., Jan. 23-27, (2011).

5. Hamed FKM. Evaluation of fatigue resistance for modified asphalt concrete mixture based on dissipate energy concept. Ph.D. thesis. Darmstadt, Germany: Technische Universität Darmstadt; (2010).

6. Soleymani HR, Zhai H, Bahia H. Role of modified binders in rheology and damage resistance behavior of asphalt mixtures. Transportation Research Record: Journal of the Transportation Research Board, No. 1875, Transportation Research Board of the National Academies, Washington, D.C. , pp.70-79.( 2004) 
7. Siddharthan, R.V., Yao, J., and Sebaaly, P.E., Pavement Strain from Moving Dynamic 3-D Load Distribution. Journal of Transportation Eng., ASCE, Vol. 124(6), Nov./Dec., pp. 557-566. (1998)

8. Siddharthan, R.V., Krishnamenon, N., and Sebaaly, P.E. Pavement Response Evaluation using FiniteLayer Approach. Transportation Research Record: Journal of the Transportation Research Board, No. 1709, Transportation Research Board of the National Academies, Washington, D.C., pp. 43-49.( 2000)

9. Kaloush, K., Biligiri, K., Nordgen, T., Zeiada, W., Rodezno, M., Souliman, M., Reed, J., and Stempihar, J. Laboratory Evaluation of Asphalt-Rubber Gap Graded Mixtures Constructed on Stockholm Highway in Sweden. Asphalt Rubber Conference, Munich, Germany (2012).

10. Texas Department of Transportation Estimates. (2015).

11. Lamptey, G., S. Labi, M. Ahmad, and K. Sinha. Life Cycle Cost Analysis for INDOT Pavement Design Procedures. Report FHWA/ IN/JTRP-2004/28. Joint Transportation Research Program, Indiana Department of Transportation and Purdue University, West Lafayette, IN, (2005).

12. Peshkin, D., Smith, K., Wolters, A., Krstulovich, J., Moulthrop, J., Alvarado, C. Preservation Approaches for High-Traffic-Volume Roadways. SHRP 2 Renewal Research : Report S2-R26-Rr-1. Washington, D.C. (2011). 